\title{
Peri-articular steroid injection improves the outcome after unicondylar knee replacement
}

\author{
A PROSPECTIVE, RANDOMISED CONTROLLED TRIAL WITH A \\ TWO-YEAR FOLLOW-UP
}

\author{
H.-N. Pang, \\ N.-N. Lo, \\ K.-Y. Yang, \\ H.-C. Chong, \\ S.-J. Yeo
}

From Singapore General Hospital, Singapore, Singapore

H.-N. Pang, MRCS Ed, MMed(Orth), Registrar

N.-N. Lo, MMed(Surg), FRCS(Ed), FAMS, Senior Consultant Orthopaedic Surgeon

K.-Y. Yang, FRCS(G), FAMS, Consultant Orthopaedic

Surgeon

H.-C. Chong, BSc(Physio),

Principal Physiotherapist

S.-J. Yeo, FRCS(Ed), FAMS

Senior Consultant Orthopaedic

Surgeon

Department of Orthopaedic

Surgery

Singapore General Hospital, 1 Outram Road, Singapore 169608, Singapore.

Correspondence should be sent to Dr H.-N. Pang; e-mail: pangheenee@ hotmail.com

(C2008 British Editorial Society of Bone and Joint Surgery doi:10.1302/0301-620X.90B6. $20550 \$ 2.00$

$J$ Bone Joint Surg $[\mathrm{Br}]$ 2008;90-B:738-44 Received 30 November 2007; Accepted after revision 30 January 2008

\begin{abstract}
We have performed a prospective double-blind, randomised controlled trial over two years to evaluate the efficacy and safety of an intra-operative peri-articular injection of triamcinolone acetonide in patients undergoing medial unicondylar knee replacement. We randomised 90 patients into two equal groups. The study group received an injection of triamcinolone acetonide, bupivacaine, and epinephrine into the peri-articular tissues at the end of the operation. The control group received the same injection mixture but without the addition of triamcinolone. The peri-operative analgesic regimen was standardised.

The study group reported a significant reduction in pain $(p=0.014$ at 12 hours, $p=0.031$ at 18 hours and $p=0.031$ at 24 hours) and had a better range of movement ( $p=0.023$ at three months). There was no significant difference in the rate of infection and no incidence of tendon rupture in either group.

The addition of corticosteroid to the peri-articular injection after unicondylar knee replacement had both immediate and short-term benefits in terms of relief from pain, and rehabilitation with no increased risk of infection.
\end{abstract}

The multifactorial aetiology of post-operative pain includes that arising from both neurogenic and inflammatory pathways. ${ }^{1}$ Parenteral opioid is associated with dose-related sideeffects such as nausea, vomiting, constipation, urinary retention, respiratory depression and drowsiness. ${ }^{2-4}$ A multimodal analgesic regime is required to cover the different pain pathways, to reduce the systemic opioid requirements and to improve the relief from pain., Intra-articular injection of morphine has been shown to provide good relief from pain after knee surgery ${ }^{7}$ although a few reports have disputed its efficacy. ${ }^{4,8}$ Various authors have described the use of peri-articular injections of various anaesthetics in combination which have given improved post-operative pain contro $^{9-11}$ and a few ${ }^{11,12-14}$ have included the use of a non-steroidal anti-inflammatory agent in the mixture used for wound infiltration. There has been concern regarding an increased risk of post-operative infection ${ }^{15,16}$ and tendon rupture $^{17,18}$ after intra-articular injection of steroid.

Our aim in this prospective, randomised, controlled study was to assess, over two years the efficacy and safety of a peri-articular injection of steroid for control of pain after unicondylar knee replacement (UKR) for medial compartment arthritis.

\section{Patients and Methods}

The study had ethical approval and written consent was obtained from each patient. Indications for UKR included minimal pain at rest, a minimum range of movement of $90^{\circ}$ with flexion contracture of not more than $5^{\circ}$ and an angular deformity of $<10^{\circ}$ of varus with minimal or no involvement of the adjacent tibiofemoral and patellofemoral compartments. ${ }^{19}$

Exclusion criteria included patients with contraindications for UKR, those undergoing bilateral UKR and those with diabetes, previous surgery to the knee, immunodeficiency, hypothyroidism, renal failure, allergies or intolerance to any component of the injection or to oral nonsteroidal anti-inflammatory medication. Ten patients were excluded based on these criteria.

A power calculation was conducted using Power and Precision statistical software version 3.0 (Biostat Inc., Englewood, New Jersey). It was determined that 36 patients were required in each group for the study to detect a difference of $25 \mathrm{mg}$ in the use of morphine in 24 hours and to achieve a power of $0.80 .^{10,20,21}$ This was based on an SD of $25 \mathrm{mg}$ in consumption of morphine per 24 hours for each patient. With this number of patients, the study would be able to detect a difference of $5^{\circ}$ (SD 20) in the post-operative range of movement and to achieve a power of 0.90 . 
A total of 90 patients who underwent medial compartment UKR by the three senior authors (N-NL, S-JY, K-YY) in 2004 and 2005 were recruited. Each surgeon contributed 30 patients and these were randomised equally into the two arms of the study by the use of randomisation tables. In the study group, 45 patients received intra-operative infiltration with a mixture which included the local anaesthetic bupivacaine $0.5 \%$ with epinephrine 1:200 000 (Astra Zeneca, Sodertalje, Sweden) and the corticosteroid triamcinolone acetonide (Kenocort; Bristol-Myers, New York, New York). In the control group, 45 patients received the local anaesthetic and epinephrine mixture but without the corticosteroid. The patients and the post-operative team who assessed them, were blinded as to which arm of the study they had been entered into.

Operative technique. Operative anaesthesia was either general or spinal. However, there was no difference between the two groups, with 23 patients receiving general and 22 spinal anaesthesia in each group. No long-acting analgesia or nerve blockade was used and spinal anaesthesia was accomplished with $10 \mathrm{ml}$ of $0.5 \%$ bupivacaine. A tourniquet was used and inflated after draping. A minimallyinvasive approach was followed by a short incision from the medial pole of the patella to the tibial tuberosity.

Caution was taken to ensure minimal disruption of the extensor mechanism. The patella was not dislocated, and the synovium of the suprapatellar pouch was not disturbed. The Zimmer MG II prosthesis (Zimmer, Warsaw, Indiana) was used in all patients with cemented femoral and metalbacked tibial components and was implanted using extramedullary femoral and tibial guides. After cementing the components, the injection was delivered into the periarticular tissues. The study group received an infiltrative mixture of $0.5 \mathrm{ml} / \mathrm{kg}^{21}$ of $1: 200000$ epinephrine and $0.5 \%$ bupivacaine diluted in $30 \mathrm{ml}$ of normal saline with $40 \mathrm{mg}$ of triamcinolone acetonide ${ }^{22}$ added to half of this mixture. The anaesthetic solution containing the corticosteroid was injected into the deep tissues including quadriceps muscle, the medial collateral ligament, the posterior capsule and the synovium, with care taken to avoid injecting the solution into either the quadriceps or the patellar tendons. The remaining half of the anaesthetic mixture, without the corticosteroid, was injected along the skin incision before closure. This was to avoid potential subcutaneous atrophy at the injection site from the triamcinolone. ${ }^{23-25}$

The control group was treated in an identical manner with diluted bupivacaine and epinephrine but without corticosteroid. No drains were used in either group and the tourniquet time was documented at the end of the operation. All the patients received $500 \mathrm{mg} \mathrm{BD}$ (twice daily) postoperative oral naproxen for two weeks and patient-controlled analgesia with a $1 \mathrm{mg}$ bolus of morphine, a lock-out time of five minutes and a maximum dose of $8 \mathrm{mg} /$ hour for 48 hours. The use of patient-controlled analgesia was an important aspect of the measurement of pain since it allowed timely and accurate measurements of the consumption of morphine.
Outcome measures. The main outcome measure was the control of post-operative pain, which was estimated by the patient using a visual analogue scale (VAS) in which zero represented no pain and ten maximum pain. The level of pain control was assessed for the first five post-operative days initially every six hours. The amount of morphine consumption was measured using the patient-controlled analgesia pump at six-hourly intervals for 48 hours.

The range of movement of each knee was documented daily by a physiotherapist (H-CC) using a goniometer. Other parameters measured included the length of time required to perform a straight-leg raise as a measure of the recovery of muscular strength and to walk independently, and the decrease in haemoglobin level on the first postoperative day. The patients were further evaluated using the Short-form (SF)-36 questionnaire ${ }^{26}$ and the Oxford knee score as modified by Dawson et $\mathrm{al}^{27}$ at intervals of three and six months and at two years. Complications such as post-operative infection and tendon rupture were documented. All the data were collected by a physiotherapist (H-CC) who was blinded to the study.

Statistical analysis. This was performed using SPSS statistical software version 11.0 (SPSS Inc., Chicago, Illinois). Univariate analysis was performed by the chi-squared or Fisher's exact tests for comparison of proportions between categorical data. The Mann-Whitney $U$ test was used to compare the non-parametric data between two independent samples. A p-value $\leq 0.05$ was considered to be statistically significant.

\section{Results}

The pre-operative clinical details were similar in both the study and control groups (Table I). The trend in the postoperative VAS score for pain showed slightly lower mean values for the patients who received steroid injection and this became statistically significant from the fourth postoperative day (Fig. 1). The patients who received the steroid injection had a significantly lower mean requirement for parenteral morphine using the patient-controlled analgesia device at 12 hours, 18 hours and 24 hours after the operation $(2.7 \mathrm{mg} /$ hour (SD 1.2) $\mathrm{p}=0.014,1.0 \mathrm{mg} /$ hour (SD 1.1) $\mathrm{p}=0.0031$ and $1.7 \mathrm{mg} /$ hour (SD 1.2) $\mathrm{p}=0.031$, respectively (all, Mann-Whitney U test)) (Fig. 2).

Patients who received a steroid injection had a greater range of movement post-operatively (Fig. 3) and this was statistically significant on the second, third, fourth and fifth post-operative days (all Mann-Whitney U test, $\mathrm{p}=0.015$, $p=0.001, p=0.004$ and $p=0.003$, respectively). This trend was continued for up to two years post-operatively with statistical significance still being demonstrated at three months post-operatively (Fig. 4).

Patients who received a steroid injection were able to perform a straight-leg raise significantly earlier at a mean of 2.2 days (1 to 3 ) after the operation compared with the control group who performed the same task at a mean of 2.7 days ( 1 to 5 ) post-operatively (Mann-Whitney U test, $\mathrm{p}=0.019$ ). 
Table I. Clinical details of the study $(n=45)$ and control $(n=45)$ groups

\begin{tabular}{|c|c|c|c|}
\hline & $\begin{array}{l}\text { Study group } \\
\text { (with steroid) }\end{array}$ & $\begin{array}{l}\text { Control group } \\
\text { (without steroid) }\end{array}$ & p-value ${ }^{*}$ \\
\hline Mean age in yrs (range) & 68 (54 to 80$)$ & 67 (54 to 80$)$ & 0.277 \\
\hline \multicolumn{4}{|l|}{ Gender (\%) } \\
\hline Male & $8(17.8)$ & $8(17.8)$ & 0.321 \\
\hline Female & $37(82.2)$ & $37(82.2)$ & 0.465 \\
\hline \multicolumn{4}{|l|}{ Side $(\%)$} \\
\hline Left & $20(44.4)$ & $23(51.1)$ & 0.156 \\
\hline Right & $25(55.6)$ & $22(48.9)$ & 0.501 \\
\hline Mean (SD) body mass index in $\mathrm{kg} / \mathrm{m}^{2}$ & $27.3(6.1)$ & $27.5(5.6)$ & 0.595 \\
\hline Mean (SD) pre-operative haemoglobin in $\mathrm{g} / \mathrm{dl}$ & $13.1(0.5)$ & $13.2(0.6)$ & 0.560 \\
\hline \multicolumn{4}{|l|}{ Type of anaesthesia (\%) } \\
\hline General & $23(51.1)$ & $23(51.1)$ & 0.734 \\
\hline Regional & $22(48.9)$ & $22(48.9)$ & 0.812 \\
\hline \multicolumn{4}{|l|}{ Mean (SD) pre-operative SF-36 questionnaire score } \\
\hline Physical functioning & $30.5(5.1)$ & $37.1(4.5)$ & 0.315 \\
\hline Role physical & $23.1(5.9)$ & $45.5(6.1)$ & 0.491 \\
\hline Role emotional & $64.6(7.2)$ & $76.3(4.9)$ & 0.138 \\
\hline Social functioning & $54.4(8.1)$ & $61.9(5.3)$ & 0.214 \\
\hline Mental health & $71.5(9.3)$ & $73.1(4.3)$ & 0.111 \\
\hline Energy/vitality & $57.2(7.2)$ & $64.3(7.2)$ & 0.109 \\
\hline Bodily pain & $37.3(7.1)$ & $47.7(7.8)$ & 0.413 \\
\hline General health perception & $70.4(6.2)$ & $70.8(3.9)$ & 0.213 \\
\hline Changes in health & $45.5(4.9)$ & $48.4(3.6)$ & 0.209 \\
\hline Mean (SD) pre-operative Oxford knee score & $20.2(4.3)$ & $20.6(5.8)$ & 0.279 \\
\hline
\end{tabular}

The control group was able to walk at a mean of 1.9 days (1 to 4 ) post-operatively and the study group earlier at a mean of 1.8 days ( 1 to 2 ) after the operation but this difference did not reach statistical significance (Mann-Whitney U test, $\mathrm{p}=0.466)$.

There was no significant difference in the mean tourniquet time between the two groups (Mann-Whitney U test, $\mathrm{p}=0.429)$. The study group had a significantly lower mean decrease in haemoglobin level (Mann-Whitney U test, $\mathrm{p}=0.028$ ) (Table II). Neither the SF-36 nor the Oxford knee score showed any statistically significant difference between the groups at the three-month, six-month and twoyear follow-up (Table II). There was no significant difference in the rate of infection (Fisher's exact test, $\mathrm{p}=0.382$ ) between the groups. In each case the infection was superficial and responded to oral antibiotics. None of the patients experienced disruption of the extensor mechanism.

\section{Discussion}

Good management of post-operative pain is required to obtain effective rehabilitation after knee replacement. ${ }^{9,28}$ Traditionally, this has been provided by epidural analgesia or peripheral nerve blockades. ${ }^{29,30}$ However, these methods are technically demanding, costly and associated with potential side-effects. ${ }^{3,4}$ Some studies have shown improved pain scores and a decreased use of opiate analgesia with soft-tissue injection of local anaesthetic agents ${ }^{10,11}$ while others have been unable to replicate these findings. ${ }^{8,31-33}$ Recently, a multimodal wound infiltration technique has been reported ${ }^{9,10,12}$ which has been found to be safe and simple to perform. Toftdahl et al ${ }^{14}$ compared local peri- and intra-articular infiltration with a continuous femoral nerve block, and demonstrated better post-operative relief from pain and faster rehabilitation with no increased risk in patients who received the local infiltration. We have added triamcinolone to our infiltration and found it to be effective and safe in post-operative pain control and rehabilitation in UKR.

Although this was a small study with only 90 patients, the number was sufficient to demonstrate a statistically significant difference in the short-term functional outcome between the two groups.

The post-operative pain after knee replacement may result from trauma to the soft tissue or bone. ${ }^{34}$ Several authors had proposed the presence of opioid receptors in the synovial membrane. ${ }^{7,31}$ Vendittoli et al $^{10}$ reported that 


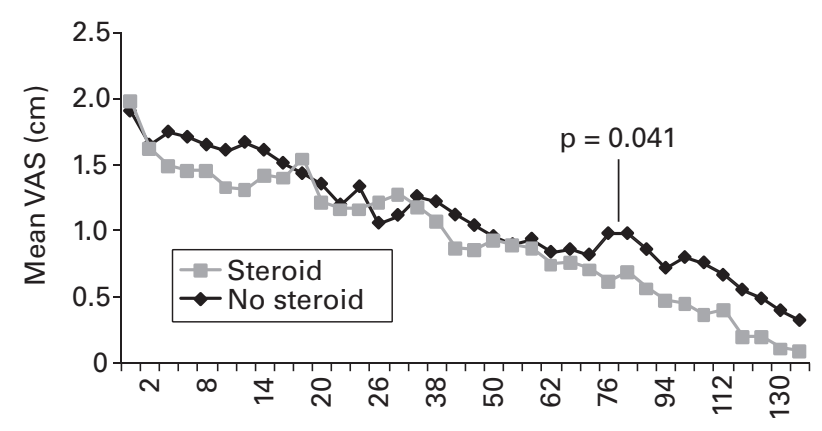

Time after surgery (hrs)

Fig. 1

Graph showing the mean visual analogue scale (VAS) scores for both groups after surgery.

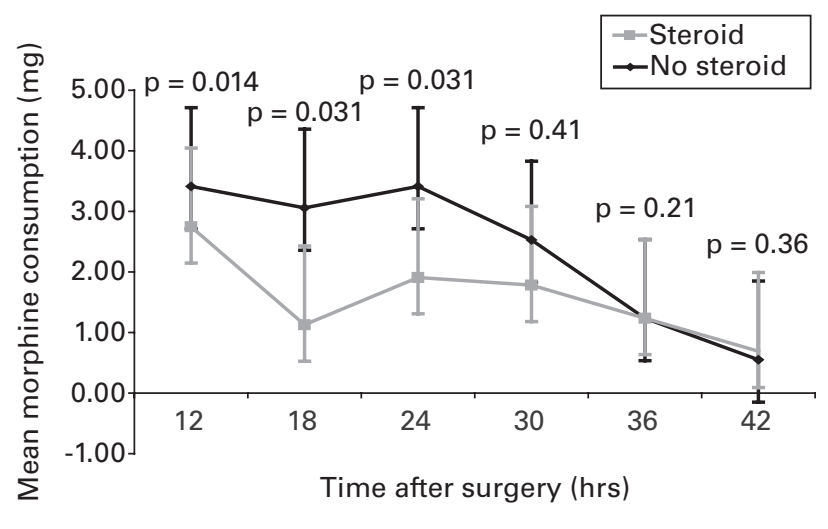

Fig. 2

Graph showing the mean (SD) morphine usage in patient-controlled analgesia in both groups up to 42 hours after surgery ( $p$-values derived using the Mann-Whitney $U$ test).

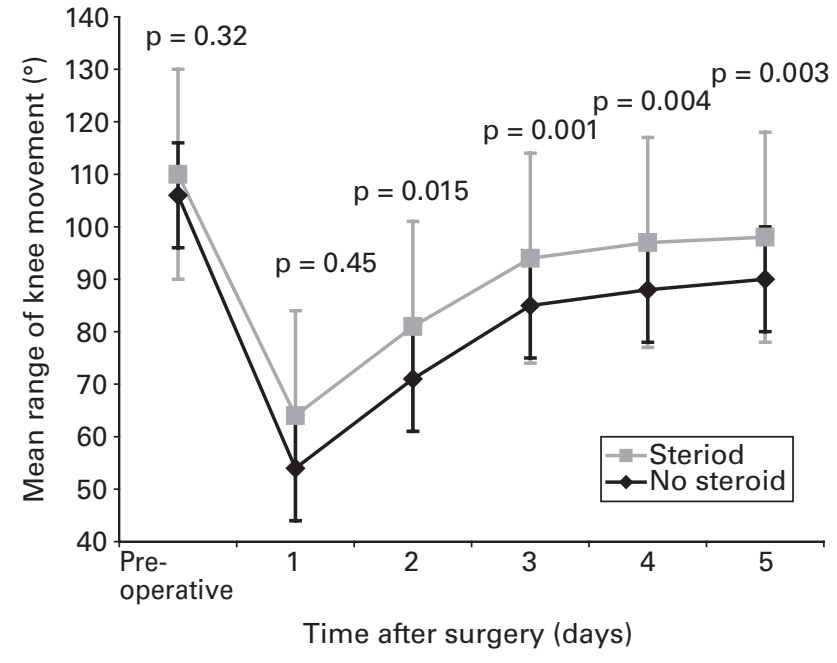

Fig. 3

Graph showing the mean range of movement immediately postoperatively for both groups. Error bars are given ( $p$-values derived using the Mann-Whitney U test). the intra-operative peri-articular injection of analgesia allowed direct visualisation and accurate placement of the injection into the injured tissues and nerve endings. In addition, the entrapment of the medication within the soft tissue enhanced and prolonged the analgesic blockade, and decreased the leakage from the wound. ${ }^{10}$

In addition to the direct effect, the use of local anaesthesia may enhance relief from pain by inhibiting the neuroendocrine stress response to surgery. ${ }^{35}$ The use of $0.5 \%$ bupivacaine has been shown to be effective in patients after arthroscopy. ${ }^{36,37}$ Badner et $\mathrm{al}^{38}$ reported that the mean serum concentration remained well below the toxic levels in patients who received up to $30 \mathrm{ml}$ of $0.5 \%$ bupivacaine intra-articularly. Lombardi et al ${ }^{11}$ found no intra-operative or peri-operative complications directly related to the injection. The addition of epinephrine to the injection helps to reduce the toxicity of the local anaesthetic by keeping it localised to the area of injection. ${ }^{39}$ Lombardi et al ${ }^{11}$ and Karaoglu et $\mathrm{al}^{40}$ were able to demonstrate diminished blood loss after the release of the tourniquet when epinephrine was present in the injection.

The anti-inflammatory action of the corticosteroid involves disrupting the prostaglandin and cyclo-oxygenase pathways at several levels. ${ }^{41}$ In summary, glucocorticoids 
Table II. Comparison of the results in the two groups

\begin{tabular}{|c|c|c|c|}
\hline & $\begin{array}{l}\text { Study group } \\
\text { (with steroid) }\end{array}$ & $\begin{array}{l}\text { Control group } \\
\text { (without steroid) }\end{array}$ & p-value ${ }^{*}$ \\
\hline Mean (SD) tourniquet time in minutes & $55 \quad(2.5)$ & $54(3.1)$ & 0.429 \\
\hline Mean (SD) decrease in haemoglobin in $\mathrm{g} / \mathrm{dl}$ & $2.1 \quad(0.5)$ & $2.5(0.3)$ & 0.028 \\
\hline \multicolumn{4}{|l|}{ At six months post-operatively } \\
\hline \multicolumn{4}{|l|}{ Mean (SD) SF-36 questionnaire score } \\
\hline Physical functioning & $60.1(6.7)$ & $55.6(7.6)$ & 0.241 \\
\hline Role physical & $72.3(5.9)$ & $69.1(8.1)$ & 0.491 \\
\hline Role emotional & $89.4(4.6)$ & $87.3(9.1)$ & 0.513 \\
\hline Social functioning & $83.2(7.6)$ & $79.4(6.7)$ & 0.467 \\
\hline Mental health & $79.2(7.1)$ & $75.5(6.3)$ & 0.159 \\
\hline Energy/vitality & $71.8(9.1)$ & $69.6(8.2)$ & 0.281 \\
\hline Bodily pain & $69.5(5.9)$ & $66.4(7.1)$ & 0.109 \\
\hline General health perception & $75.4(7.1)$ & $73.7(5.1)$ & 0.195 \\
\hline Changes in health & $72.3(5.6)$ & $70.1(4.7)$ & 0.385 \\
\hline Mean (SD) Oxford knee score & $37.8(5.9)$ & $35.4(7.1)$ & 0.485 \\
\hline
\end{tabular}

\begin{tabular}{|c|c|c|c|}
\hline \multicolumn{4}{|l|}{ At two years post-operatively } \\
\hline \multicolumn{4}{|c|}{ Mean (SD) SF-36 questionnaire score } \\
\hline Physical functioning & $61.2(7.4)$ & $57.1(5.6)$ & 0.376 \\
\hline Role physical & $73.4(7.9)$ & $71.2(4.1)$ & 0.456 \\
\hline Role emotional & $88.1(6.7)$ & $86.7(6.7)$ & 0.629 \\
\hline Social functioning & $84.5(8.1)$ & $82.4(9.3)$ & 0.319 \\
\hline Mental health & $81.9(8.3)$ & $76.2(6.9)$ & 0.295 \\
\hline Energy/vitality & $73.1(6.9)$ & $71.9(9.2)$ & 0.362 \\
\hline Bodily pain & $73.0(7.1)$ & $68.9(7.3)$ & 0.524 \\
\hline General health perception & $78.2(5.3)$ & $74.3(8.3)$ & 0.296 \\
\hline Changes in health & $76.9(7.2)$ & $74.7(8.3)$ & 0.726 \\
\hline Mean (SD) Oxford knee score & $38.4(6.1)$ & $37.3(7.8)$ & 0.319 \\
\hline Infection (\%) & $2(4.4)$ & $2(4.4)$ & 0.382 \\
\hline Tendon rupture $(\%)$ & $0(0.0)$ & $0(0.0)$ & 0.215 \\
\hline
\end{tabular}

act directly on nuclear steroid receptors to control the rate of synthesis of mRNA and proteins. This has a number of consequences, including changes in T- and B-cell function, changes in white blood cell activity, alterations in the level of cytokines and enzymes and inhibition of phospholipase A2 resulting in a reduction in pro-inflammatory derivatives of arachidonic acid. ${ }^{42}$ Injection of steroids into the surrounding soft tissues can therefore provide good relief from pain by reducing the inflammation at the sites of surgical trauma ${ }^{43,44}$ and can decrease blood loss through the reduction of these prostaglandins, in particularly the vasodilating agents ${ }^{45}$ prostacyclin and prostaglandin $\mathrm{D}_{2}$ and $\mathrm{E}_{2}$. The enhanced pain relief with the use of steroids in the infiltration was in line with the results of the study by Parvataneni et $\mathrm{al},{ }^{46}$ who used methylprednisolone acetate in their injections.

Triamcinolone acetonide injectable suspension is an insoluble synthetic glucocorticoid with anti-inflammatory action and is suitable for intra-articular use. ${ }^{47}$ It has an extended duration of effect which exceeds that of methylprednisolone and may be sustained over a period of several weeks. Studies indicate that after a single intramuscular dose of $60 \mathrm{mg}$ to $100 \mathrm{mg}$ of triamcinolone acetonide, adrenal suppression occurs within 24 to 48 hours and then gradually returns to normal, usually in 30 to 40 days. $^{47,48}$ Our study demonstrated an improved mean range of movement in patients who received peri-articular injections of steroid which was statistically significant at three months but still demonstrated a difference beyond this period. We postulate that the insoluble particles of triamcinolone acetonide persist in the tissues and continue to exert anti-inflammatory effects over time, thereby reducing post-operative fibrosis and scarring. Consequently, patients enjoy a better range of movement and a more rapid rehabilitation.

Local injection of corticosteroids has been used extensively in musculoskeletal tissues and joints without impairment of wound healing or other complications. ${ }^{46,47,49,50}$ The reported complications of intra-articular steroids are rare and include septic arthritis, tissue atrophy and osteonecrosis. ${ }^{51}$ By observing strict asepsis and stringent exclusion criteria, we found no increase in infection at follow-up at two years. Caution was taken to avoid injecting steroid into the patellar tendon and there was no incidence of tendon rupture in our patients. 
We have demonstrated the efficacy and safety of an intra-operative peri-articular injection of bupivacaine, epinephrine and triamcinolone after UKR. The patients who received the steroid injection had better relief from pain, faster rehabilitation and less blood loss, with no increased risk of infection or tendon rupture at follow-up at two years.

No benefits in any form have been received or will be received from a commercial party related directly or indirectly to the subject of this article.

\section{References}

1. Riegler FX. Update on perioperative pain management. Clin Orthop 1994;305:283-92.

2. Albert TJ, Cohn JC, Rothman JS. Patient-controlled analgesia in a postoperative total joint arthroplasty population. J Arthroplasty 1991;6(Suppl):23-8.

3. Singelyn FJ, Deyaert M, Joris D, Pendeville E, Gouverneur JM. Effects of intravenous patient-controlled analgesia with morphine, continuous epidural analgesia, and continuous three-in-one block on postoperative pain and knee rehabilitation after unilateral total knee arthroplasty. Anesth Analg 1998;87:88-92.

4. DeWeese FT, Akbari Z, Carline E. Pain control after knee arthroplasty: intraarticular versus epidural anesthesia. Clin Orthop 2001;392:226-31.

5. Kehlet H. Surgical stress: the role of pain and analgesia. $\mathrm{Br} J$ Anaesth 1989;63:189-95.

6. Mallory TH, Lombardi AV Jr, Fada RA, Dodds KL. Anesthesia options: choices and caveats. Orthopaedics 2000;23:919-20.

7. Kalso E, Tramèr MR, Carroll D, McQuay HJ, Moore RA. Pain relief from intraarticular morphine after knee surgery: a qualitative systematic review. Pain 1997;71:127-34.

8. Mauerhan DR, Campell M, Miller JS, et al. Intra-articular morphine and/or bupivacaine in the management of pain after total knee arthroplasty. J Arthroplasty 1997; 12:546-52.

9. Busch CA, Shore BJ, Bhandari R, et al. Efficacy of periarticular multimodal drug injection in total knee arthroplasty: a randomised trial. J Bone Joint Surg [Am] 2006;88-A:959-63.

10. Vendittoli PA, Makinen P, Drolet $\mathbf{P}$, et al. A multimodal analgesia protocol for total knee arthroplasty: a randomized, controlled study. J Bone Joint Surg [Am] 2006;88-A:282-9.

11. Lombardi AV Jr, Berend KR, Mallory TH, Dodds KL, Adams JB. Soft-tissue and intra-articular injection of bupivacaine, epinephrine, and morphine has a beneficial effect after total knee arthroplasty. Clin Orthop 2004;428:125-30.

12. Reilly KA, Beard DJ, Barker KL, et al. Efficacy of an accelerated recovery protocol for Oxford unicompartmental knee arthroplasty: a randomised controlled trial. Knee 2005;12:351-7.

13. Rømsing J, Møiniche S, Østergaard D, Dahl JB. Local infiltration with NSAIDs for postoperative analgesia: evidence for a peripheral analgesic action. Acta Anaesthesiol Scand 2000;44:672-83

14. Toftdahl K, Nikolajsen L, Haraldsted V, et al. Comparison of peri- and intraarticular analgesia with femoral nerve block after total knee arthroplasty: a randomized clinical trial. Acta Orthop 2007;78:172-9.

15. Papavasiliou AV, Isaac DL, Marimuthu R, Skyrme A, Armitage A. Infection in knee replacements after previous injection of intra-articular steroid. J Bone Joint Surg $[B r]$ 2006;88-B:321-3.

16. Kaspar S, De V de Beer J. Infection in hip arthroplasty after previous injection of steroid. J Bone Joint Surg [Br] 2005;87-B:454-7.

17. Ismail AM, Balakrishnan R, Rajkumar MK, Lumpur K. Rupture of patellar ligament after steroid infiltration: report of a case. J Bone Joint Surg [Br] 1969;51B:503-5

18. Sweetnam R. Corticosteroid arthropathy and tendon rupture. J Bone Joint Surg [Br] 1969;51-B:397-8.

19. Kozinn SC, Scott R. Unicondylar knee arthroplasty. J Bone Joint Surg [Am] 1989;71-A:145-50.

20. Hirst GC, Lang SA, Dust WM, Cassidy JD, Yip RW. Femoral nerve block: single injection verus continuous infusion for total knee arthroplasty. Reg Anesth 1996;21:292-7.

21. Ng HP, Cheong KF, Lim A, Lim J, Puhaindran ME. Intraoperative single-shot "3in -1 " femoral nerve block with ropivacaine $0.25 \%$, ropivacaine $0.5 \%$ or bupivacaine $0.25 \%$ provides comparable 48 -hr analgesia after unilateral total knee replacement. Can J Anaesth 2001;48:1102-8.
22. American Collage of Rheumatology Subcommittee on Osteoarthritis guidelines. Recommendations for the Medical Management of Osteoarthritis of the hip and knee: 2000 update. Arthritis Rheum 2000;43:1905-15.

23. Dyment PG. Local atrophy following triamcinolone injection. Pediatrics 1970;46:136-7.

24. Gomez EC, Berman B, Miller DL. Ultrasonic assessment of cutaneous atrophy caused by intradermal corticosteroids. J Dermatol Surg Oncol 1982;8:1071-4.

25. Reddy PD, Zelicof SB, Ruotolo C, Holder J. Interdigital neuroma: local cutaneous changes after corticosteroid injection. Clin Orthop 1995;317:185-7.

26. Ware JE Jr, Sherbourne CD. The MOS 36-item short-form health survey (SF-36). I: conceptual framework and item selection. Med Care 1992;30:473-83.

27. Dawson J, Fitzpatrick R, Murray D, Carr A. Questionnaire on the perceptions of patients about total knee replacement. J Bone Joint Surg [Br] 1998;80-B:63-9.

28. Etches RC, Warriner CB, Budner $\mathbf{N}$, et al. Continuous intravenous administration of Ketorolac reduces pain and morphine consumption after total hip or knee arthroplasty. Anesth Analg 1995;81:1175-80.

29. Fischer HB, Simanski CJ. A procedure-specific systematic review and consensus recommendations for analgesia after total hip-replacement. Anaesthesia 2005;60:1189-202

30. Ilfeld BM, Gearen PF, Enneking EK, et al. Total knee arthroplasty as an overnight-stay procedure using continuous femoral nerve blocks at home: a prospective feasibility study. Anesth Analg 2006;102:87-90.

31. Klasen JA, Opitz SA, Melzer C, Thiel A, Hempelmann G. Intraarticular, epidural, and intravenous analgesia after total knee arthroplasty. Acta Anaesthesio Scand 1999;43:1021-6.

32. Ritter MA, Koehler M, Keating EM, Faris PM, Meding JB. Intra-articular morphine and/or bupivacaine after total knee replacement. J Bone Joint Surg $[\mathrm{Br}]$ 1999:81-B:301-3

33. Browne C, Copp S, Reden L, Pulido P, Colwell C Jr. Bupivacaine bolus injection versus placebo for pain management following total knee arthroplasty. J Arthroplasty 2004;19:377-80.

34. Estèbe JP, Kerebel C, Brice C, Lenaoures A. Pain and tourniquet in orthopaedic surgery. Cah Anesthesiol 1995;43:573-8 (in French).

35. Rasmussen S, Kramhøft MU, Sperling KP, Pedersen JH. Increased flexion and reduced hospital stay with continuous intraarticular morphine and ropivacaine after primary total knee replacement: open intervention study of efficacy and safety in 154 patients. Acta Orthop Scand 2004;75:606-9.

36. Geutjens G, Hambridge JE. Analgesic effects of intraarticular bupivacaine after day-case arthroscopy. J Arthros Rel Surg 1994;10:299-300.

37. Smith I, Van Hemelrijck J, White PF, Shively R. Effects of local anesthesia on recovery after outpatient arthroscopy. Anesth and Analg 1991;73:536-9.

38. Badner NH, Bourne RB, Rorabeck CH, MacDonald SJ, Doyle JA. Intraarticular injection of bupivacaine in knee-replacement operations: results of use for analgesia and for preemptive blockade. J Bone Joint Surg [Am] 1996;78A:734-8

39. Solanki DR, Enneking FK, Ivey FM, Scarborough M, Johnston RV. Serum bupivacaine concentrations after intraarticular injection for pain relief after knee arthroscopy. Arthroscopy 1992;8:44-7

40. Karaoglu S, Dogru K, Kabak S, Inan M, Halicic M. Effects of epinephrine in local anesthetic mixtures on hemodynamics and view quality during knee arthroscopy. Knee Surg Sports Traumatol Arthrosc 2002;10:226-8.

41. Uthman I, Raynauld JP, Haraoui B. Intra-articular therapy in osteoarthritis. Postgrad Med J 2003;79:449-53.

42. Creamer P. Intra-articular corticosteroid injections in osteoarthritis: do they work and if so, how? Ann Rheum Dis 1997:56:634-6.

43. Mirzai H, Tekin I, Alincak H. Perioperative use of corticosteroid and bupivacaine combination in lumbar disc surgery: a randomized controlled trial. Spine 2002;27:343-6.

44. Glasser RS, Knego RS, Delashaw JB, Fessler RG. The perioperative use of corticosteroids and bupivacaine in the management of lumbar disc disease. J Neurosurg 1993;78:383-7.

45. Thébault J, Blatrix C, Blanchard J, Panak E. A possible method to control prolongations of bleeding time under antiplatelet therapy with ticlopidine. Thromb Haemost 1982;48:6-8.

46. Parvataneni HK, Shah VP, Howard H, et al. Controlling pain after total hip and knee arthroplasty using a multimodal protocol with local periarticular injections: a prospective randomized study. J Arthroplasty 2007;22:33-8.

47. No authors listed. MedlinePlus from U.S National Library of Medicine- National Institutes of Health. 2007 information. Available at http://www.nlm.nih.gov/ medlineplus/medlineplus (date last accessed 26 August 2007). 
48. Lazarevic MB, Skosey JL, Djordjevic-Denic G, et al. Reduction of cortisol levels after single intra-articular and intramuscular steroid injection. Am J Med 1995;:370-3.

49. Holte K, Kehlet H. Perioperative single-dose glucocorticoid administration: pathophysiologic effects and clinical implications. J Am Coll Surg 2002;195:694-712.
50. Salerno A, Hermann R. Efficacy and safety of steroid use for postoperative pain relief: update and review of the literature. J Bone Joint Surg [Am] 2006;88-A:1361-

51. Hunter JA, Blyth TH. A risk-benefit assessment of intra-articular corticosteroids in rheumatic disorders. Drug Saf 1999;21:353-65. 